\title{
DESIGN OF THE BODY FRAME OF A RAIL DETECTOR
}

\author{
Jiangang Bao \\ North University of China Department of Mechanical Engineering, China; Email: \\ baojiangang@nuc.edu.cn.
}

\begin{abstract}
According to the practical needs of the railroad engineering and the applying situations of the rail detectors, the assembling parts of the detector are designed and assembled with the SolidWorks toolkit to create the threedimension model, and its reasonableness is analyzed with the help of the finite-element method.
\end{abstract}

Key words: rail detector, three-dimension modeling, SolidWorks.

\section{INTRODUCTION}

The development of the rail detector has undergone two stages: manual detecting and automatic detecting. In abroad, the application and development of the rail detector have a history of dozens of years. In developed countries today, the detection of the rail lines has been done with the detector, and manual detection is only an auxiliary way to check the defects. According to the now railroad situations, there are two kinds of working model for detection: discontinuous and continuous. The technology of the rail detector has been studied in the United States since the 1940s. After the 1970s, with the rapid development of computer technology, especially the application of the real-time data processing technique, the research of the rail detector advanced greatly. This technique enables the operation information detected by the car to be displayed real-time on the screen, the detected data to be stored and played back anytime to show the detected results. The development of the detector in China has taken two great strides, from tapping by hand to using ultrasonic rail detectors. The functions of the detectors have been updated, from the single resonance

Please use the following format when citing this chapter:

Bao, Jiangang, 2006, in International Federation for Information Processing (IFIP), Volume 207, Knowledge Enterprise: Intelligent Strategies In Product Design, Manufacturing, and Management, eds. K. Wang, Kovacs G., Wozny M., Fang M., (Boston: Springer), pp. 165-170. 
detectors to micro-computer, semi-intelligence, and multi-channel ultrasonic ones. In order to raise the detecting efficiency of the rail defects to improve the railroad maintenance, large rail detectors are introduced, which have the advantages of rapid detecting speed, high reliability, and good repeatability. Now, there are many types of small detectors, produced home and abroad. The manually operated detector has a multi-probe structure, and the frame is made of light material. It is light and easy to handle to be used for moving on many types of rail and detecting. For example, the home-made Model MW37-GT-1C rail detector is a practical precision instrument. The latest Model SGT-2000 rail detector is a new, special digitalized rail detector, but it is inferior to the foreign products. It moves forwards only, and damages the probes if moving backwards. Its frame structure is complex and needs to be optimized, and its weight needs to be further reduced.

\section{DESIGN OF THE DIGITALIZED THREE- DIMENSION MODEL}

Here, the body frame of the rail detector is divided into six units: the probe support section, the bed, the box, the pulling section, the rack section, and the motion controlling section, with each made up of many parts.

The design of the three-dimension model of the detector and the assembly of the units and parts are carried out with the now popular threedimension designing software, SolidWorks.

The bed of the detector is used to support the water box and the rack section, part of which is channeled. The channeled structure has many advantages, (1) high intensity, to bear very heavy pressure; (2) light weight, to be easily used for field work, and (3) material-saving, to reduce the cost greatly in mass production and thus improve economic benefits.

The bed is made up of 8 parts, the supporting arms of the body frame (2 pieces), the upright beams ( 2 pieces), the horizontal beams, the sliding rails for the probe support section ( 2 pieces), and the fixed base for the push bar.

\section{DESIGN AND MODEL OF THE PROBE SUPPORT ARMS}

There are two supporting arms for the probes, located at the front and rear ends of the detector, to be used for mounting the two probe stands and for mounting the rubber wheels. When the probe supporting arms are down, the clamping bar is linked with the bed to make the probes very close to the rail to detect; when the arms are up, the rubber wheels touch the land to 
support the detector to move on land. The arms are linked with the doorshape frame in the bed by its middle part.

The arms are designed to move forwards and backwards, without damaging the probes. The final arm is shown as in Figure 1.

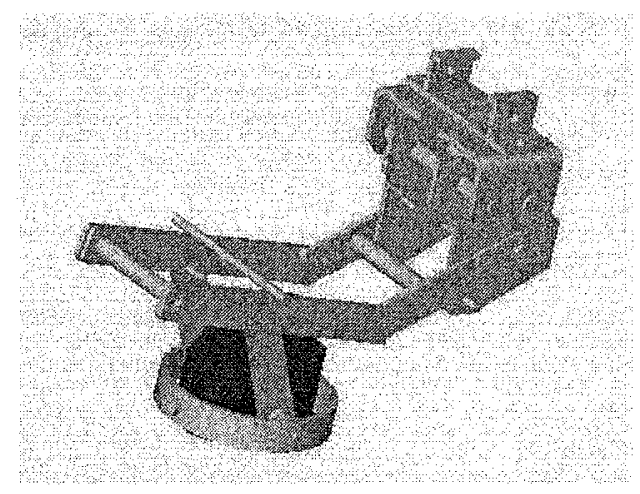

Figure 1. Two-way motion probe arm

\section{DESIGN OF THE RACK SECTION AND THE BOX}

The rack section, the largest part of the detector, is mounted on the top of the body frame, whose shape is shown as in Figure 2. The box is mainly used to accommodate the ultrasonic controlling machine, Its three-dimension model is shown as in Figure 3.
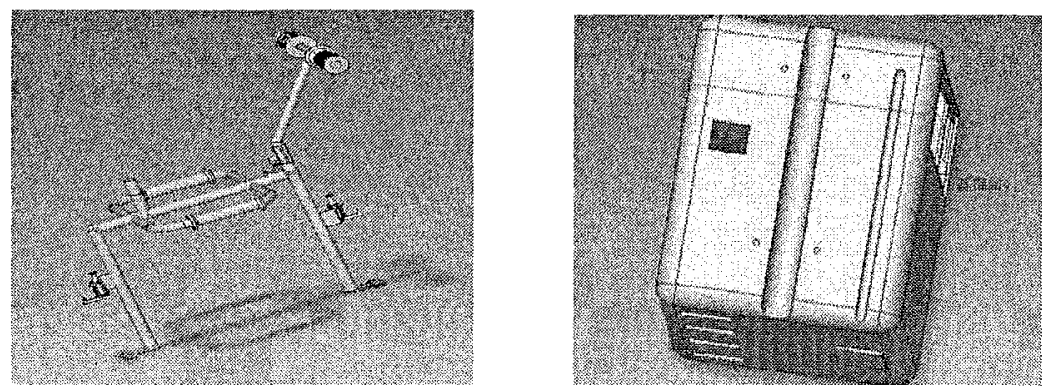

Figure 2 The rack section.

Figure 3 The three-dimension model of the box. 


\section{THREE-DIMENSION MODELS OF THE MOTION CONTROLLING AND PULLING SECTIONS}

The motion controlling and pulling sections are primarily used to perform the motion functions of the detector, that is, to retract the wheels and to move back and forth on the rail. Their three-dimension models are shown as in Figure 4 and Figure 5.

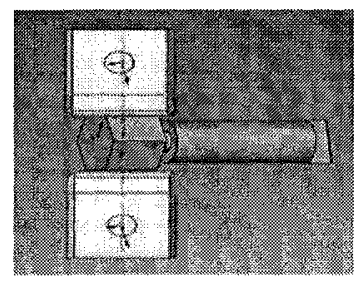

Figure 4 The motion controlling section.

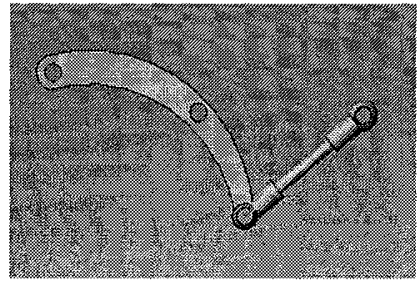

Figure 5 The pulling section.

\section{GENERAL ASSEMBLY OF THE RAIL DETECTOR}

The above parts are assembled in the SolidWorks software, and examined through interference ${ }^{[2]}$ (supplied by SolidWorks, to detect the problems in time and solve them). Now the design of the model of the detector is accomplished, whose general assembly is shown as in Figure 6.

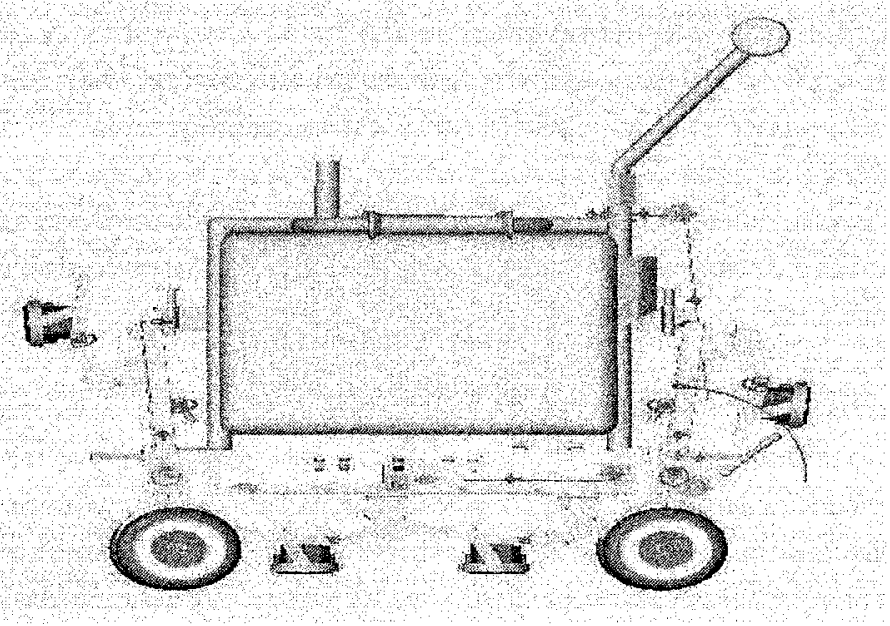

Figure 6 The general assembly of the new-type rail detector. 


\section{DYNAMIC SIMULATION}

The first is to clarify the linking and driving relationships between the parts to determine which characteristics of the product is to be simulated and solved.

1) Determining which parts are added into the motion model

The pulling and relieving function of the InteliMotion explorer is used to point out which parts are motion parts, which are fixed and still, and which have closely fixed relationship with others. The COSMOSMotion tool is used to create the motion link for an assembled part in the motion model. Certainly, the user can manual create the motion link if there is not a suitable assembled part.

2) Imposing restrictions on the motion of the mechanical unit

The user can set the freedom of motion for the moving unit. The motion can be horizontal or rotary.

3) Adding additional load

The user can add to the parts in the mechanical unit additional load, external force or torque.

4) Simulating and checking the results

The user pushes the button to call the simulation function. The program will solve the problems with the motion of the mechanical unit: displacement, rate, accelerated velocity, and the acting forces between the moving parts in the unit.

After the simulation, the user can see the animated simulation results, which helps the user to know the details of the motion of the mechanical unit and exchange the results with others.

\section{CONCLUSION}

In this paper, the parts of the rail detector has been systematically classified and analyzed, and with the application of SolidWorks and the advanced modeling techniques -..- parametric modeling and characteristic modeling, related parameters are determined and characteristics are classified, and the three-dimension model of the body frame of the rail detector is created. Finally, the motion simulation module is used to determine the form and parameters of the motion of the mechanical unit and create the spatial motion model in order to determine the reasonableness of 
the structure and the consistency of the motion with the theoretical analysis. The pilot rail detector practically works well.

\section{REFERENCES}

1. Liu Lijuan. Digitalized Simulation Design and development of Web-based Products. M.S. Thesis of North University of China. 2005.

2. Xie Hong $\&$ Shi Wei. Three-dimension Design of Assembled Units with SolidWorks. Tool Techniques, 2002. 